\title{
LAS ELECCIONES DE FIN DE SIGLO EN EL CONO SUR \\ Claudia Ibargüen*
}

$E_{n}$ un período de poco más de tres meses tuvieron lugar procesos electorales en los tres países del Cono Sur: Uruguay, Argentina y Chile. Las tres naciones vivieron dictaduras militares de rasgos similares y también transitaron en la década de los ochenta a sistemas de competencia electoral abierta. Aunque persisten diferencias en cuanto a la solidez de sus estructuras democráticas, es ya innegable que los tres países cuentan con procedimientos institucionalizados de transferencia de poder y que el espectro de la dictadura va quedando atrás. Estos comicios, asimismo, dejaron al descubierto procesos similares y comparables. En los tres se percibió la exigencia de forjar amplias coaliciones y alianzas para acceder al poder. En dos de los tres países se dio la llegada de nuevos actores políticos que anteriormente no existían o no contaban con verdadera pujanza electoral. Asimismo, hoy en día, en todos estos países los perdedores son leales. Aceptan los resultados, felicitan a los ganadores y se absorben a la tarea de ser oposición.

En los tres países las últimas elecciones dieron cuenta de insatisfacciones compartidas, en parte por la adopción de los cánones de la economía de mercado, ante la que se alzan las voces que demandan una mejor distribución del ingreso. Las iniquidades en la distribución del ingreso fue un tema central de los tres procesos. En Uruguay y

* Departamento de Estudios Internacionales, ITAM. 


\section{CLAUDIA IBARGÜEN}

Argentina, principalmente, el problema de la corrupción gubernamental fue el otro asunto cardinal. La izquierda se alzó con el triunfo en Argentina y Chile y se quedó a poco camino de hacer lo mismo en Uruguay. Pero la izquierda de hoy no es la misma de hace treinta años. En los tres países la izquierda juega actualmente un papel moderado. Aceptan las reglas del juego económico internacional, pero arguyen que a esto lo conjugan con una perceptividad más aguda de los sectores que se han quedado atrás. Es interesante explorar los tres procesos electorales por la similitud del pasado reciente de los tres países, pero también por las semejanzas en los temas que se han vuelto importantes y en las maneras de hacer política.

\section{Uruguay}

En Uruguay las elecciones de fin de milenio, efectuadas el 31 de octubre, comenzaron con resultados un tanto singulares, al adjudicarse el primer lugar la coalición de izquierda por encima de los partidos tradicionales, el Blanco y el Colorado. Aunque el Frente Amplio (la coalición

24 de izquierda) venía fortaleciéndose desde sus inicios en 1971, fue un suceso inédito en la medida que era la primera vez en 169 años de vida institucional que una fuerza de izquierda derrotaba a los dos partidos de centro derecha en una votación nacional. En la segunda vuelta, sin embargo, el desenlace se aproximó a los cánones tradicionales de la política uruguaya con la victoria del candidato de centro derecha del Partido Colorado, Jorge Battle. Como expresó Pablo Rodríguez, "el Encuentro Progresista y el Frente Amplio (EP-FA) marcaron un quiebre en la historia política del Uruguay, pero no la partieron en dos". 1

Los resultados finales del proceso electoral uruguayo arrojan una serie de incógnitas acerca del futuro balance de fuerzas partidistas y en general sobre el panorama político en los años venideros. Por un

${ }^{1}$ Pablo Rodríguez, "El Colorado Jorge Battle ganó por 8 puntos las elecciones contra Tabaré", Página 12, 29 de noviembre de 1999. 
lado, la contundente presencia electoral de la coalición de izquierda, aunque no se trata de una situación completamente nueva, en esta ocasión sí amenaza seriamente con resquebrajar la histórica alternancia bipartidista entre blancos y colorados. Sin embargo, el que la izquierda finalmente fracasara en arrebatarle la Presidencia a los dos partidos ejemplifica un status quo arraigado. Blancos y colorados, rivales históricos, también están prestos a unir fuerzas para hacer frente a la nueva amenaza proveniente de la izquierda.

Por tanto, se explorarán dos fenómenos. Primero, el cambio que se está gestando con la llegada indiscutible de la izquierda al mapa político. Y, vinculado con esto, a qué respondió el espectacular resultado en la primera vuelta del Frente Amplio. Cuáles fueron las razones que permitieron un aumento de la izquierda al grado de casi ganarle la Presidencia a dos partidos que llevan la totalidad (con excepción del período de dictadura militar) de la vida institucional Uruguaya turnándose el Edificio Libertad. En segundo plano, y relacionado con lo anterior, se intentará hacer un esbozo de porqué la izquierda no consiguió amarrar su liderazgo inicial en la segunda vuelta.

Los resultados de los comicios en octubre arrojaron los siguientes resultados: La coalición de izquierda el Encuentro Progresista FrenteAmplio logró un $38.5 \%$ de los votos, por delante del Partido Colorado (31.3\%) con Jorge Battle como candidato, y el Partido Blanco (21.2\%) del ex presidente Luis Lacalle. ${ }^{2}$ En el mes que corrió entre la elección de fin de octubre y la definitoria de segunda vuelta el 28 de noviembre, el partido blanco y el colorado unieron fuerzas. Aunque Lacalle ya estaba descalificado, puesto que sólo los dos partidos con más alto porcentaje jugarían en la contienda de balotaje, éste hizo un llamado a sus partidarios para apoyar a Battle en oposición a Vásquez. La suma de blancos y colorados obtuvo un $51.6 \%$ por ciento de los votos, despojando a Vásquez de sus expectativas de triunfo.

- 2 Francesc Relea, "El ganador en Uruguay en la primera vuelta observa una 'revolución cautelosa' en América”, El País, 2 de noviembre de 1999. 


\section{CLAUDIA IBARGÜEN}

Uruguay comparte con los otros dos países del Cono Sur determinadas características. En los tres se puede hablar de una cierta homogeneidad social, aunque ésta es mucho mayor en Uruguay. Los tres cuentan con clases medias fuertes y al igual que los otros dos países del Cono Sur, Argentina y Chile, Uruguay vivió los efectos de una cruenta dictadura militar que corrió de 1973 a 1985 . También en forma similar a las otras dos naciones, antes de la entrada de los militares Uruguay contaba con partidos políticos de vieja cepa. Es la presencia de estos partidos políticos lo que varios analistas advierten como gran parte de la explicación de la eventual transición a la democracia. La democracia uruguaya, anterior al golpe, centraba su fortaleza en sus bien instituidos partidos políticos y una poderosa identificación ciudadana con una de estas dos agrupaciones. Inclusive, dentro de las filas castrenses los militares mantuvieron, durante el período de dictadura, una identificación individual ya fuera por blancos o colorados. La anuencia militar para un retorno a la democracia emanó, en gran medida, de que ninguno de los dos partidos alternativos representó una amenaza u opción peligrosa en los términos definidos por la institución militar de aquella época. ${ }^{3}$ Los blancos y los colorados, han sido las agrupaciones políticas por excelencia. Han sido también centristas, moderadas, pro sistema y habian monopolizado, hasta ahora, el poder político.

Estos dos partidos políticos han sufrido un deterioro acelerado en el transcurso de un par de décadas, particularmente desde el retorno de la democracia. Uruguay, el país de dos partidos dominantes con el agregado de partidos de izquierda que nunca sobrepasaban el techo del $20 \%$ de votación, ha sido dejado atrás. El politólogo Luis Eduardo González muestra la evolución de los partidos establecidos (Blanco y Colorado) y la de sus desafiantes (el Frente Amplio, luego Encuentro

${ }^{3}$ Para una discusión más completa de las motivos que impulsaron la transición a la democracia en Uruguay véase, Juan Linz y Alfred Stepan, Problems of Democratic Transition and Consolidation, Southern Europe, South America and Post Communist Europe, 1996, Baltimore, Johns Hopkins University Press, p. 151-65. 
Progresista-Frente Amplio). El resultado es simple y contundente: el bloque de los lemas tradicionales viene perdiendo votantes en forma regular y constante (unos 6 puntos porcentuales en cada período de gobierno) mientras los gana el bloque de las izquierdas. ${ }^{4}$ En la elección presidencial de 1994 el bipartidismo tradicional comenzó a transformarse en una contienda electoral de tres fuerzas divididas de manera bastante equivalente. En esa ocasión, en la que todavía no existía la segunda vuelta, el Partido Colorado de Julio María Sanguinetti se alzó con la victoria al captar el $31.4 \%$ de los votos. Los otros dos candidatos, Tabaré Vásquez por el Frente Amplio y Alberto Volonte del Partido Blanco o Nacional, prácticamente empataron con una leve delantera del segundo de tan sólo 3,000 votos. ${ }^{5}$ Por tanto, el resultado logrado por la izquierda hace un par de meses no puede ser descrito como un fenómeno completamente nuevo. La llegada del FA se venía gestando por lo menos desde 1989 cuando Vásquez conquistó la alcaldía de Montevideo, el puesto de elección popular más importante después de la presidencia. Para frenar el imparable incremento en el apoyo popular a la izquierda los dos partidos tradicionales impulsaron una reforma constitucional en 1996. Fue en esta ocasión que se introdujo el balotaje o segunda vuelta en caso de no obtener ningún candidato la mayoria absoluta. Es evidente que su cálculo estratégico tuvo el efecto deseado. De no haber existido la segunda vuelta Vásquez se habría alzado con el triunfo en octubre de 1999. Y es esto, precisamente, lo que es distinto a las experiencias pasadas. En esta ocasión la coalición de izquierda en verdad arañó la Presidencia. Asimismo, con estas elecciones logró convertirse en el primer grupo parlamentario por número de diputados y senadores. Por primera vez se necesitará al FA para

${ }^{4}$ Marcelo Pereira, "Una batalla ganada y perdida", Brecha, $\mathrm{n}^{\circ} 731,3$ de diciembre de 1999 .

${ }^{5}$ Base de Datos Políticos de las Américas, (1999) Uruguay: Resultados de elección presidencial de 1999, [internet], Georgetown University y Organización de Estados Americanos, en: http://www.georgetown.edu/pdba/ Elecdata/Arg/arg99.html, 1 de noviembre 1999. 


\section{CLAUDIA IBARGÜEN}

lograr los dos tercios requeridos para aprobar las leyes más importantes. De mantenerse las tendencias, remarcan los estudiosos del sistema uruguayo, el FA logrará la mitad más uno en las próximas elecciones. "Es un proceso electoral que aún no ha dado a los frente amplistas la mayoría absoluta, pero que se la dará en los próximos comicios." 6

¿Cómo ha logrado la izquierda ganar espacios y a qué se debe su caudal electoral en la última elección? Primero es importante resaltar nuevamente que el Frente Amplio no era una coalición que irrumpiera por primera vez en noviembre pasado en la escena política. Como se mencionó, fue formada en 1971, un par de años antes del golpe militar. Durante los trece años de la dictadura se vio obligado a ocultarse. Con el retorno de la democracia la izquierda paulatinamente fue ganando apoyo por parte del electorado. El crecimiento ininterrumpido en las últimas cuatro elecciones se dio de manera gradual, como la mayor parte de los procesos en el Uruguay.

El crecimiento de la izquierda, de una fuerza exigua a lo que reflejan los números hoy en día, es producto, en gran medida, del desgaste de dos formaciones políticas que a juicio de muchos se ha repartido cotos de poder por demasiado tiempo, obstaculizando la entrada de fuerzas nuevas. El que ambas agrupaciones tengan su identidad propia pero se sitúen en la centro derecha del espectro político, cada vez parece más restrictivo para ciudadanos que buscan nuevas opciones.

Los tiempos mundiales también han permitido que la izquierda no sea percibida como sinónimo de rièsgo. Aunque todavía subsiste dentro de ciertos sectores un miedo arraigado a cualquier agrupación de índole izquierdista y en efecto, como veremos más adelante, esto se aprovechó en detrimento del FA, los socialistas que pueblan hoy en día los círculos de poder en América Latina, incluida Uruguay, ya no hablan el lenguaje de lucha con que se expresaban en los sesenta y setenta. Su bandera no se centra más en cambios radicales en la economía. El Frente Amplio de Tabaré así como la alianza liderada por Fernando de la Rúa en Argentina enfocaron su discurso de campaña,

${ }^{6}$ Marcelo Pereira, op. cit. 
no a criticar el modelo económico que se ha instalado en estos dos países sino la ausencia de sensibilidad hacia las iniquidades sociales y la corrupción de los gobiernos pasados. En efecto, estos dos asuntos fueron el núcleo de las propuestas de ambos candidatos. "Nuestra política económica será totalmente gradualista excepto en dos temas: la lucha contra la corrupción y contra la pobreza."7 Los socialistas de hoy son profundamente pragmáticos y moderados. Vásquez no es la excepción, desde el primer momento se esforzó en transmitir un mensaje de tranquilidad a la comunidad financiera internacional y a los inversores. ${ }^{8}$ En cuanto ganó la primera ronda y se vislumbró la posibilidad seria de alcanzar la Presidencia reunió a tres grupos de asesores que viajaron para explicar su programa y asegurar en los centros financieros internacionales que, de llegar al poder, su comportamiento no debería inquietarles. ${ }^{9}$

Otra interpretación del buen resultado del FA examina las decisiones personales de los electores. Éstos buscan recompensar con su voto una gestión pasada eficiente. En términos generales se considera que el gobierno de Vásquez en Montevideo fue competente. Esto explica que el feudo electoral del FA se encuentre localizado en la capital.

Una explicación original interpreta el aumento de simpatía a la izquierda, en un país tradicionalmente conservador, como un gesto profundamente conservador. Bajo esta óptica, el incremento en la adhesión al FA no respondería a una búsqueda de cambio. En los últimos 10 años (los de mayor crecimiento de la izquierda) Uruguay en efecto cambió atravesando un período de crecimiento económico, modernización y apertura hacia el mundo. Estos cambios han generado incerti-

7 "No traemos aventuras ni soluciones mágicas", El País, 22 de noviembre de 1999, p. 5.

${ }^{8}$ Ibid.

${ }^{9}$ En Bruselas se reunieron con miembros de la Unión Europea, en Washington con emisarios del Fondo Monetario Internacional, El Banco Mundial y el Banco Interamericano de Desarrollo. En las capitales del MERCOSUR hicieron lo mismo con funcionarios de este mercado común. 


\section{CLAUDIA IBARGÜEN}

dumbres, miedos, desconfianza y finalmente inseguridad. El Estado benefactor que antaño era de los más extensos de América Latina se contrajo. Según este argumento, existe una cultura uruguaya, aldeana, que da prioridad a la seguridad sobre los riesgos, que desconfía de la competitividad, que prefiere la seguridad de un empleo público mal pagado que la incertidumbre de un mercado laboral abierto. ${ }^{10}$ En los últimos años el mensaje predominante ha sido que las estabilidades del pasado ya no existen y que para sobrevivir hay que competir. E1 votar a la izquierda, por tanto, es una respuesta de esa vieja cultura política uruguaya reacia al cambio y a lo nuevo. La izquierda encuentra adeptos con un discurso que despotrica contra los males que ha traído el neoliberalismo y la globalización y habla con añoranza de los tiempos cuando los uruguayos no tenían de qué preocuparse. Esta versión, sin duda apunta hacia aspectos interesantes de la cultura política uruguaya, sin embargo no explica porqué fue precisamente en las zonas rurales donde ganó Battle, mientras que en las ciudades, donde menos existiría esta supuesta cultura política 'aldeana', fue donde la izquierda obtuvo sus mejores números.

El día posterior a las elecciones, el FA parecía encaminado a romper por primera vez el monopolio Blanco-Colorado e instaurar el primer gobierno socialista en Uruguay. ¿A qué se aduce el que Tabaré no haya podido concretar? Aunque sus acciones confirman a un candidato socialista de mueva generación, similar a los otros del Cono Sur, el Frente Amplio oficialmente no ha renunciado al marxismo. Esto, obviamente, fue recordado con insistencia por los partidarios de Battle en los dos meses que mediaron antes del balotaje. La intención del recordatorio fue presentar una eventual victoria de Vásquez como sinónimo de caos en Uruguay. Entre los argumentos lanzados con el propósito de descalificar al candidato del Frente Amplio se llegó a insinuar que su proyecto se acercaba más al de Allende en Chile que al de Felipe González en España (con quien los socialistas latinoamericanos les gusta compa-

${ }^{10}$ Juan Carlos Doyenart, "El nuevo y el viejo Uruguay", El Observador, 6 de noviembre de 1999. 
rarse para probar que es posible ser al mismo tiempo socialista y pro sistema.) "El mensaje de la insinuación fue claro: Vásquez en el gobierno abriría un período de inestabilidad en Uruguay que quién sabe, podría terminar violentamente." 11 En particular el campamento colorado-blanco subrayó la intención de los socialistas de establecer un impuesto sobre la renta. Según Eduardo Galeano, en la propaganda manipulada por los medios gobiernistas se manejó a esta política como "una invención marxista para despojar a los trabajadores y a los jubilados de lo poco o nada que tienen". ${ }^{12}$ Es interesante advertir los resabios de los turbulentos primeros años de los setenta y cómo en Uruguay este tipo de etiquetas, aparentemente anacrónicas, todavía despierta temores y suscita reflejos automáticos de inmovilismo entre la población, en particular, la rural. Para aprovechar las ventajas con que contaban desde el punto de partida, los colorados trataron de presentar estos comicios como una opción ideológica entre demócratas y marxistas; y los frenteamplistas por su parte de mostrarlas como una elección programática entre lo mismo de siempre y un viraje hacia algo mejor. ${ }^{13}$ Los colorados en última instancia tuvieron éxito con la propaganda del miedo, especialmente en las áreas no urbanas. Sin embargo, lo que a final de cuentas permitió la victoria de Battle fue la alianza, en los primeros días posteriores a la primera ronda, entre colorados y blancos. La suma de un poco más de $20 \%$, originalmente sufragado para Lacalle, parece haber sido traspasada casi en su totalidad al bando Colorado.

Esta alianza conformada bajo la exigencia de una segunda vuelta está teniendo ahora, poco antes de que Battle asuma el gobierno sus primeros conflictos por la paralización de negociaciones sobre el Gabinete. Como se advirtió en el momento en que se constituyó la alianza, los colorados tuvieron que pactar varias carteras importantes con sus

11 "Felipe González o Salvador Allende", El País, lunes 29 de noviembre de 1999.

${ }^{12}$ Eduardo Galeano, "Téoría de la Vaca", Página 12, 3 de diciembre de 1999.

${ }^{13}$ Marcelo Pereira, "Empezó la segunda vuelta los de arriba y los de abajo", Brecha, 5 de noviembre de 1999. 


\section{CLAUDIA IBARGÜEN}

rivales históricos. Lacalle dejó claro que el apoyo Nacional (Blanco) no sería gratuito y que el próximo gobierno tendría "el sabor y la fuerza que le sabe imprimir el Partido Nacional".

Es difícil vislumbrar exactamente cómo se repartirán las fuerzas políticas uruguayas, pero es un hecho que la izquierda ya es un jugador importante. En un futuro el Frente Amplio podría permutar el entorno político al que los uruguayos están acostumbrados, aunque lo que se perfila, sin embargo, aun no es claro. Se puede tratar de un tripartidismo o tal vez, si la izquierda sigue obligando a los partidos tradicionales a una alianza permanente, o de un bipartidismo modificado en el cual blancos y colorados unan fuerzas para hacer frente al nuevo inquilino del panorama político. El mismo Battle ha sido precursor desde hace años de la idea de formar un Partido Republicano para unir a ambos partidos. Si la izquierda sigue su camino ascendente será una propuesta que tendrá que ser cavilada con seriedad.

\section{Chile}

32 De manera semejante a lo acontecido en Uruguay, las elecciones llevadas acabo el 12 de diciembre de 1999 en Chile inauguraron el arribo de una fuerza política nueva. A diferencia de Uruguay, sin embargo, esta fuerza política es de derecha, no de izquierda, y su éxito no se vislumbraba apenas unos meses antes. Joaquín Lavín, candidato de coalición, logró articular partidos de derecha como la Unión Democrática Independiente (UDI) y la Renovación Nacional (RN) y obtuvo la votación más elevada para la derecha chilena desde la década de los años treinta. ${ }^{14} \mathrm{El}$ resultado del 12 de diciembre arrojó un empate técnico (menos de medio punto porcentual) entre el candidato Socialista de la Concertación, Ricardo Lagos y el derechista Joaquín Lavín, de Acción por Chile. Esto obligó a una segunda vuelta para determinar al ganador.

14 "Sorprende al oficialismo chileno el resultado de Lavín", La Jornada, 14 de diciembre de 1999. 
El 16 de enero del 2000 Lagos finalmente se alzó con un triunfo cerrado al ganar por $51.3 \%$ mientras que Lavín conquistó el $48.69 \%$, una diferencia de votos de tan sólo 180,000. Los números indican el éxito de la campaña de Lavín. Es inobjetable que éste supo atraer votos que anteriormente habían sido para la Concertación. El sorprendente apoyo a Lavín, cuya única experiencia política comprendía la alcaldía de Las Condes, la comuna más acaudalada de Chile, constituye una incógnita de las elecciones de fin de siglo en Chile. La elección en diciembre era la tercera desde el retorno a la democracia tras la dictadura militar de 17 años. En las dos elecciones anteriores la Concertación, liderada por candidatos de la Democracia Cristiana, había ganado con relativa holgura.

Es interesante percibir que quienes se enfrentaron pacíficamente en las urnas en diciembre provienen precisamente de los dos sectures antagónicos del pasado. Lagos de larga militancia socialista colaboró con el gobierno del depuesto presidente Salvador Allende. Lavín a su vez fungió como asesor económico de Pinochet y hasta antes de la elección era un vociferante defensor de Pinochet y los logros del gobierno militar. En 1988 Augusto Pinochet aceptó cumplir con un apartado de la Constitución de 1980 que fijaba ese año para la convocatoria a un plebiscito sobre la prolongación del régimen militar. Este resquicio, única vulnerabilidad de la Constitución militar, fue aprovechado por organizaciones civiles y partidos políticos de antaño para enfrentar a Pinochet en sus términos. La alianza que exhortó a votar por el 'No', se convirtió en la coalición electoral de las primeras elecciones postdictadura en 1989. La Concertación de Partidos por la Democracia unió a dos sectores enfrentados durante la presidencia de Salvador Allende, el de los socialistas y el de la democracia cristiana. ${ }^{15}$ En

${ }^{15} \mathrm{La}$ Concertación estaba compuesta por 17 partidos. Los más importantes eran la democracia cristiana, los radicales, los social demócratas y los socialistas, que a su vez estaban divididos en Partido Socialista y Partido por la Democracia. Véase William C. Smith, Carlos Acuña y Eduardo Gamarra (eds.), Markets and Structural Reform in Latin America Argentina, Brazil, Bolivia and Mexico, 1993, Miami, North South Center, 217-33. 
1989 la Concertación alcanzó la presidencia con un cómodo margen sobre su adversario de derecha Hernán Büchi. En contraste con Uruguay, los militares mantuvieron la lealtad de sectores civiles que habían apoyado el golpe de 73, ahora transformados en la derecha política. Sin embargo, esta derecha estuvo fragmentada en las dos primeras elecciones. Mientras tanto la Concertación logró instituirse como una fuerza política permanente y para la segunda elección, con Eduardo Frei como candidato, también ganó de manera incuestionable con un $57 \%$ del voto. ${ }^{16}$ En la tercera prueba se auguraba que la Concertación ganaría la contienda de manera tan desahogada como lo habían logrado sus antecesores, pero sin embargo, conforme avanzó la campaña, varias circunstancias se conjugaron para rectificar el pronóstico inicial.

Son precisamente estas circunstancias las que se intentarán dilucidar. 1) ¿Qué cambió de la coyuntura chilena para alcanzar el caudal de votos logrados por la derecha? 2) ¿La nueva coalición forjada por Lavín fue un fenómeno de una sola elección o se perfila la derecha como un jugador de largo plazo? 3) ¿Cuál es el futuro previsible de la Concertación?

Al arrancar la campaña presidencial con Lagos al frente de la boleta concertacionista se manejaron varias especulaciones, pero ninguna que previera un final tan apretado. Se insinuó que al ser un aspirante proveniente del sector socialista de la Concertación, se presentarían temores en el sector empresarial. Asimismo, algunas voces vaticinaron que la contienda de 1999 estaría marcada por un clima de enfrentamiento generado por el descontento de las Fuerzas Armadas ante la detención de Pinochet en Londres. ${ }^{17}$ Paradójicamente, ni los empresarios mostraron un nerviosismo desmesurado, ni el caso Pinochet se convirtió en un asunto clave en las agendas de campaña de los dos principales

${ }^{16}$ En las elecciones de 1993 Frei, de la Democracia Cristiana triunfó en las primarias sobre Ricardo Lagos. Frei posteriormente le otorgaría la cartera de Obras Públicas a Lagos.

17 "Chile aprendió de su historia", La Tercera, domingo 12 de diciembre de 1999. 
contendientes. El impresionante alcance de la derecha no estuvo relacionado ni con miedos vinculados al pasado ideológico de Lagos ni tampoco con la irritación de los militares y las cúpulas empresariales porque su Senador vitalicio estuviera enfrentando acusaciones en el exterior. De hecho, los tópicos que siguen dividiendo a los chilenos desde el retorno a la democracia: la cuestión de los desaparecidos, los derechos humanos y la permanencia de candados que obstaculizan el pleno ejercicio de la democracia, estuvieron conspicuamente ausentes en los ejes de discusión. ${ }^{18}$

Lo anterior apunta a la primera explicación de las conquistas Lavinistas. Lavín en vez de explotar la ira de ciertos grupos por la detención de Pinochet, como se podría haber inferido por su pasado político, en una decisión estratégica de campaña que resultó fructífera, se alejó de la figura del general retirado. Asimismo, logró no mostrarse demasiado aliado con los sectores más ricos a los que había servido en Las Condes. Lavín pudo presentar a los herederos del régimen militar como una opción viable que de ninguna manera era sinónimo de gobierno dictatorial o de una subordinación incondicional a Pinochet.

En efecto, las decisiones de táctica política: dónde poner el acento de la campaña, qué asuntos resaltar y cuáles ignorar fueron muy acertados. Al evadir no sólo su pasado y sus vinculaciones, sino también los temas políticos tradicionales (derechos humanos, remanentes de la dictadura, futuro de Pinochet) calculó, correctamente, que a muchos chilenos, particularmente de las generaciones más nuevas, les aburren y rehuyen estas discusiones. En declaraciones durante la campaña dejó claro que no perdería su tiempo conjeturando acerca del caso Pinochet. "Para

${ }^{18} \mathrm{La}$ Constitución que rige a Chile fue aprobada en 1980 en pleno régimen militar. Entre los candados que fueron negociados a la salida del poder de los militares fueron 9 curules en el Senado, que hasta la fecha son designadas por las Fuerzas Armadas. La Concertación no ha logrado llegar a un 60\% necesario para cambiar o enmendar las reglas orgánicas aprobadas durante el régimen de Pinochet y que establecen las reglas del juego del sistema electoral, la composición de las cortes, y las agencias reguladoras. Véase Linz y Stepan, op. cit., 206-9. 


\section{CLAUDIA IBARGÜEN}

lo que es la marcha del país, da lo mismo la situación de Pinochet. Es difícil decirlo pero la mayoría del país está en otra." ${ }^{19}$ El candidato eligió una estrategia que emanó de la percepción de que los chilenos, en la coyuntura actual, esperan propuestas y soluciones concretas y no polémicas abstractas.

El tono de la campaña de Lavín también fue ingenioso. Con un sólido apoyo de marketing político se apoderó de la bandera de cambio. Logró mostrarse como el candidato moderno, con inquietudes más allá de lealtades partidistas. Esta táctica tuvo impacto aprovechando la natural erosión de la Concertación después de dos gobiernos consecutivos. Lavín supo explotar ese síntoma de deslustre y de cansancio, presentándose a sí mismo como la personificación del cambio, lo nuevo, la juventud, y muy importante, el futuro, no el pasado. El equipo de Alianza por Chile logró desplegar un imaginario publicista en el que su candidato Lavín ofrecía juventud, innovación y futuro, y Lagos, por el contrario, vejez, tradición y pasado.

La situación particular de la economía en el año de 1999 con una profundización del ciclo recesivo y un aumento de la cesantía, tampoco ayudó a Lagos. "Existe una relación lineal entre el aumento de Lavín (medido según la encuesta reconocida como más seria la del CEP) y el incremento del desempleo desde el segundo semestre de 1998."20 Lo que parece indicar que cada vez más son temas cotidianos como la economía, el empleo o la educación los que determinan el voto de la gente. La consigna de cambio fue tan popular precisamente por que Chile cruzaba por un momento de crisis económica. Con este panorama fue más seductor un lema de cambio que Lagos, que en cierto modo era la personificación del continuismo. En vastos sectores del país se dio un voto de censura y descontento hacia el Gobierno a raíz de la crisis económica. $^{21}$

19 "Los equipos de Lagos y Lavín definieron ayer su discurso para enfrentar la decisión de Straw", La Tercera, 12 de enero del 2000.

${ }^{20}$ Cavallo, "Las 50 claves de las campañas de Lagos y Lavín", La Tercera, jueves 9 de diciembre de 1999.

21 "El mensaje de las urnas", La Tercera, martes 14 de diciembre de 1999. 
A pesar de que la táctica de Lavín fue inteligente, el resultado de la primera ronda también se puede aducir a problemas en el campamento Laguista. En primer término, el socialista tuvo que gastar un vasto capital político para ganar las internas de su propia coalición en contra del demócrata-cristiano Andrés Zaldivar. Seguidamente, los socialistas tuvieron que enfocar sus esfuerzos en evitar la dispersión de la DC y amarrar su apoyo. Para ello la campaña fue silenciada durante algo más de 45 días, entregando la totalidad del escenario a su adversario. ${ }^{22}$ En las 6 semanas que mediaron entre la primera y la segunda vuelta Lagos se vio obligado a modificar su aproximación a los votos. Primero pidió a Soledad Alvear, antigua ministra de justicia demócratacristiana, formar parte de su equipo, tratando con ello de atraer el voto femenino que se había volcado hacia Lavín. Asimismo desarrolló un estilo más directo y menos académico y aumentó sus promesas. Al final es probable que Lagos pudiera adelantar en las urnas a Lavín por la adhesión a la Concertación de los pequeños partidos que quedaron fuera de la segunda vuelta.

Lagos es el primer socialista que llega a la Moneda desde el golpe de 1973. Al igual que Allende en su momento, no es un presidente fuerte. Su gestión se verá enormemente comprometida por presiones de ambos lados. La derecha hoy en día no puede ser ignorada, puesto que el voto a Lavín fue de casi la mitad del electorado. Asimismo, la militancia comunista hoy se puede sentir parcialmente responsable de la victoria del candidato socialista. De los 150,000 nuevos votos que optaron por Lagos, es muy posible que un buen porcentaje provenga de $\operatorname{los} 230,000$ que en la primera vuelta se pronunciaron por el Partido Comunista. 23

Lagos, tiene por delante una gestión complicada. El primer obstáculo que ya está enfrentando son las divisiones internas dentro de la misma Concertación. Un segmento dentro del oficialismo conocido como

$$
{ }^{22} \text { Op. cit. }
$$

${ }^{23}$ Antonio Caño, "Lagos convoca a la derecha a trabajar juntos para culminar la transición en Chile”, El País, martes 18 de enero del 2000. 


\section{CLAUDIA IBARGÜEN}

'los autoflagelantes' (por ser altamente críticos de los logros de los dos primeros gobiernos Concertacionistas) comenzó a rearticularse. Lagos buscó inmediatamente bajar el perfil de este grupo, pero sin marginalizarlos, puesto que necesita el apoyo de todos los sectores. ${ }^{24}$ Este primer incidente marca seguramente el tono de otros conflictos similares en el futuro próximo. Después de esta elección que puso al descubierto que la Concertación ya no es invencible, probablemente se darán procesos de auto-examen al interior de la Concertación. Lagos comienza su mandato agotado y con problemas internos. La reactivación de la economía y la disminución del desempleo serán claves para que el nuevo presidente logre encaminarse exitosamente y deje atrás el amargo episodio de las elecciones.

Lavín supo aprovechar una coyuntura particular en Chile. Sus logros en las urnas dan cuenta de ello. Sin embargo ¿se puede prever que esta nueva coalición de derecha será un actor permanente en la escena política chilena? Algunos así lo auguran, "todo parece indicar que el sistema de partidos políticos pasó desde una identificación ideológica con los tres tercios tradicionales, izquierda, centro y derecha, hacia un sistema formado por dos grandes coaliciones de carácter centrípeto". ${ }^{25}$ No menos que Lagos, Lavín también enfrenta dificultades al interior de su coalición para afianzar la unión política. En esta ocasión Lavín logró subordinar a los miembros tradicionales de la derecha, pero ¿es factible que la RN y la UDI se mantengan unidas? No queda muy claro. Aunque ambas agrupaciones son de derecha guardan puntos de vista opuestos, o difíciles de conciliar. Por ejemplo, Lagos prometió actuar durante su Administración para disolver los candados que aún existen; también se ha manifestado a favor de apoyar una ley de divorcio (Chile es el único país de América Latina que no cuenta con una), pero dentro

${ }^{24}$ Véase, 'Frenó lucha de 'autoflagelantes' y 'autocomplacientes' Lagos exige fin de rivalidades en Concertación", La Tercera, 27 de enero del 2000.

${ }^{25}$ Alfredo Rehren, “'Marca esta elección el inicio de un nuevo ordenamiento político? De los tres tercios a dos grandes coaliciones", La Tercera, lunes 13 de diciembre de 1999. 
de la derecha hay grados muy distintos de respaldo a estas ofertas. Para poseer más referencias que nos den una respuesta al mapa político chileno que se dibujará en los próximos años será necesario esperar a las elecciones parlamentarias del año siguiente.

\section{Argentina}

Las primeras elecciones de fin de siglo en el Cono Sur también tomaron lugar en Argentina. Éstas fueron las únicas en las que no fue necesaria la definición mediante una segunda vuelta. Asimismo, en contrapartida con los otros dos países, en las encuestas el ganador ya se perfilaba de manera clara con antelación. En contraste con Uruguay y Chile, sin embargo, donde se reeligió al mismo partido o coalición que había estado en el poder, en Argentina la elección otorgó la victoria a la oposición. Fernando de la Rúa candidato de la alianza compuesta por la Unión Cívica Radical y el Frepaso obtuvo el triunfo sobre el candidato justicialista (o peronista) Eduardo Duhalde por un amplio margen. Después de diez años de mandato justicialista un candidato radical había llegado de nuevo a la Casa Rosada. E1 hecho no fue fortuito. Las huellas de esta victoria se pueden atribuir básicamente a tres motivos. Primero, la concreción de un pacto político entre la UCR y el Frepaso con el objetivo específico de batir al justicialismo en las urnas. Segundo, el éxito de esta coalición opositora en las elecciones de 1997. $\mathrm{Y}$ por último, el desgaste de los justicialistas aunado a escándalos persistentes que acabaron por minar la confianza pública en la Administración de Menem.

El último presidente radical Raúl Alfonsín había dejado prematuramente la presidencia en 1989 ante una terrible crisis económica. El primer cambio de estafeta entre un partido y otro, después de la caída del régimen militar, ocurrió en un clima de incertidumbre macroeconómica e hiperinflación. El abanderado justicialista, Carlos Menem, logró en un par de años la estabilidad cambiaria y el retorno de la tranquilidad. Este logro fue explotado por Menem para mantenerse en el poder. 


\section{CLAUDIA IBARGÜEN}

Manipuló un cambio constitucional que le permitió postularse para un segundo mandato. ${ }^{26}$ Menem ganó en 1995 y su partido también conquistó la mayoría en el Congreso. Durante su gestión logró una impresionante concentración de poder en torno a su persona y la transformación del partido peronista en un ente totalmente distinto al fundado por Juan Perón. ${ }^{27}$

Como se mencionó anteriormente, la llegada de De la Rúa se puede rastrear en la creación de la Alianza en 1997. A principios de ese año, el panorama no era promisorio para la UCR. Los números constataban que en las elecciones para el Congreso y la intendencia de Buenos Aires los peronistas eran prácticamente invencibles. Lo que es más, en la elección presidencial de 1995 la centenaria Unión Cívica Radical había caído hasta el tercer puesto, detrás de una agrupación nueva llamada el Frente País Solidario (Frepaso). El Frepaso era una amalgama de centro izquierda compuesta por el Frente Grande, la Unidad Socialista, la Democracia Cristiana, y El País. Pero el Frepaso aunque había tenido un desempeño brillante en sus primeras elecciones como partido político, no contaba con una estructura partidaria a escala nacional que le permitiera realmente aspirar a posibilidades de triunfo. En esta situación la UCR y el Frepaso coincidieron en que la única fórmula para desafiar a Menem y al justicialismo era sumar fuerzas. E1 2 de agosto de 1997 las cúpulas de ambas organizaciones acordaron marchar unidos a los comicios de ese año. Confiaban en que la imagen positiva del Frepaso combinado con el poderoso enramado partidista del radicalismo les ofrecería mayores probabilidades de triunfo.

${ }^{26}$ Se conoce como el Pacto de Olivos al arreglo entre Menem y Alfonsín para lograr la enmienda constitucional que ofrecía la posibilidad de la reelección presidencial. Para más información sobre este acontecimiento véase: Carlos Acuña, ed., La nueva matriz política argentina, 1995, Buenos Aires, Nueva Visión.

${ }^{27}$ Véase, Marcelo Cavarozzi y Oscar Landi, “'Menem: El fin del Peronismo? (Crisis y postración en la Argentina)", Documento CEDES, 66, 1991. 
En efecto, su unión rindió frutos. Para la intendencia de Buenos Aires la Alianza postuló a Graciela Fernández Meijide, su mejor carta. En ese importante puesto ganó la Alianza así como varios escaños de diputados. Aunque las elecciones en 1997 de ninguna manera fue una derrota completa para el peronismo, mostró que la maquinaria peronista no era imbatible. Con esas elecciones, las primeras que los peronistas perdían estando en el poder, se comenzó a construir el camino para que la población reconociera que había una verdadera opción de gobierno al Partido Justicialista.

En las elecciones de 1997 Menem intentó vender nuevamente la noción de que la derrota del peronismo era equivalente a un peligroso retomo a los aciagos días de la hiperinflación. Enfrentado con la Alianza, el oficialismo arremetió exhibiendo a ésta como una opción arriesgada para la continuidad de la estabilidad financiera. Esta táctica había funcionado en el 95 y Menem apostó nuevamente a que la memoria colectiva de la crisis económica daría la victoria a sus correligionarios. Pero la Alianza rápidamente disipó miedos de los segmentos económicos. Se pronunció a favor la estabilidad, la convertibilidad y el equilibrio fiscal y prometió no revertir las privatizaciones. En esencia anunciaron anticipadamente que no tenían previsto abandonar el proyecto económico establecido durante los años menemistas. Con esto, la Alianza neutralizó exitosamente el arma más poderosa del discurso oficialista. ${ }^{28}$

En 1997 se comenzaron a moldear nuevas expectativas y exigencias. Los argentinos, que ya no estaban tan preocupados por un retorno a la inestabilidad de su moneda, comenzaron a reclamar mejores niveles de empleo, mejor funcionamiento de su sistema de justicia y mayor atención a los temas de salud y educación. El resultado fue un voto de castigo de una población irritada ante el uso constante de la excusa de la estabilidad macroeconómica para cometer todo tipo de abusos.

Para la contienda electoral de 1999 el candidato de la oposición aliancista empezó su campaña en noviembre de 1998, mientras que

28 "La Elección: Diez hechos claves de la campaña electoral", El Clarín, domingo 26 de octubre de 1997. 


\section{CLAUDIA IBARGÜEN}

Duhalde no fue proclamado hasta mayo. El desfase respondió a que Carlos Menem planeaba, en contra de lo que estipula la Constitución, una segunda reelección consecutiva. Sólo después de que el ambicioso Presidente agotó todos los caminos para continuar en el poder, se alineó con Duhalde sin mucho entusiasmo. Por tanto, el candidato peronista no nada más tuvo que enfrentar el desgaste societal de su partido sino también las obstrucciones del Presidente con quien históricamente había tenido desavenencias. Inclusive en los meses anteriores a la elección era ya evidente que Menem inclusive prefería la victoria de De la Rúa a la de su copartidario. La derrota podría ser imputada directamente a la persona de Duhalde y Menem quedaría como líder del PJ, un lugar idóneo para ir cimentando su candidatura para el 2004. ${ }^{29}$

Sin duda, la ausencia de un respaldo sólido por parte de Menem fue determinante en el tropiezo duhaldista. Pero aun más influyente fue la capacidad de la Alianza para mostrarse como responsables en el ámbito económico pero drásticamente distintos en su ética administrativa. De la Rúa aprovecho su imagen de hombre serio, en contrapartida a la imagen frívola y despilfarradora de Menem. La Alianza logró convencer durante la campaña a una ciudadanía harta de escándalos de corrupción, que su gestión sería transparente y frugal. Duhalde en cambio, llevaba a cuestas no nada más la percepción generalizada que la Administración de Menem estaba corroída por la corrupción sino también la turbia actuación de la policía de su provincia, involucrada en decenas de escándalos, atentados, asesinatos a sueldo y asaltos a bancos en los últimos seis años. De la Rúa en sus decenas de spots, en una elección caracterizada por un impresionante uso de los medios de comunicación, apuntaron a lo correcto: el cambio, la probidad, y 'la refundación moral' del país.

En cuanto asumió De la Rúa subrayó el cambio de tono al gobierno saliente. De la altisonancia de la era menemista pasó a un protagonismo presidencial casi mínimo. La comunicación de las primeras decisio-

${ }^{29}$ El día después de la elección la ciudad de Buenos Aires amaneció empapelada con publicidad que rezaba: "Cuídelo, Menem para el 2004". 
nes de su gestión no las hizo él, como era hábito en Carlos Menem, sino sus propios funcionarios. ${ }^{30}$ En otro acto significativo para su imagen de sobriedad, de la Rúa se negó a utilizar el lujoso avión presidencial viajando en líneas comerciales. Un articulista político resumió la futura Administración de la Alianza: "Hay sólo tres certezas para las futuras líneas políticas de la administración delarruista: habrá cambios profundos en los estilos y en los modos de los gobernantes; y habrá cambio más de forma que de fondo en el manejo de la economía y de las relaciones internacionales." 31

Aunque la ciudadanía clamó rotundamente en las urnas que estaba hastiada de un gobierno con tan poca sensibilidad social y ética, la gestión de la Alianza no se prevé sencilla. Las elecciones dejaron un precario equilibrio de poderes: De la Rúa será el Presidente, pero tendrá un Senado en contra, un virtual empate en la Cámara de Diputados y 18 de las 24 provincias en manos de gobernadores peronistas. Mientras Buenos Aires, la más grande de ellas, y donde vive un tercio de la población nacional, fue arrebatado a Fernández Meijide por Carlos Ruckauf, ex vicepresidente y duro menemista. ${ }^{32}$ En otras palabras, Menem todavía es clave para ofrecer gobernabilidad. En lo que ya se está adivinando no tendrá tanta facultad, es para proteger a sus antiguos colaboradores de demandas por malversación de fondos. Ya se estableció una oficina anticorrupción y se han iniciado más de 50 expedientes relacionados con posibles delitos cometidos por funcionarios de la gestión anterior. ${ }^{33}$

30 "Una herencia que fue regada con sangre", El Clarin, domingo 19 de diciembre de 1999.

31 Joaquín Morales Solá, "Los primeros equilibrios de De la Rúa", La Nación, 31 de octubre de 1999.

32 "Regresa la rivalidad Menem-Alfonsín", La Tercera, 27 de octubre de 1999.

${ }^{33}$ Las investigaciones más avanzadas corresponden al pago de sobreprecios en las secretarías de Medio Ambiente, que dirigió María Julia Alsogaray. Véase al respecto: "Corrupción: el Gobierno lleva a la Justicia a Sofovich y María Julia", El Clarín, viernes 28 de enero del 2000. 


\section{CLAUDIA IBARGÜEN}

El repaso de las elecciones que tuvieron lugar en los últimos días del siglo en el Cono Sur arroja varias interrogantes y ciertas coincidencias.

Los resultados señalan que el éxito electoral dependerá en gran medida de la capacidad para forjar coaliciones electorales amplias. Es probable que los radicales no habrían ganado en Argentina sin los votos adicionales proporcionados por sus compañeros de fórmula. En Chile, el buen desempeño de la derecha se puede adjudicar a la habilidad de Lavín para atraer con su candidatura a distintas corrientes de derecha que anteriormente se habían postulado por separado. En Uruguay, la victoria de Battle se debió al pacto de solidaridad de los dos partidos tradicionales. Es probable que un futuro blancos y colorados si pretenden seguir ganando tengan que continuar actuando en conjunción.

Otra afinidad que se pudo apreciar a la luz de estos comicios fue la de los temas en los que se hizo énfasis durante la campaña. En los tres países discusiones sobre la consolidación de la democracia y el legado de los regímenes autoritarios va quedando atrás. Las nuevas generaciones que no vivieron en carne propia estos períodos y que se unen a la fuerza de trabajo exigen otras prioridades. Aunque esto no quiere decir que el tema de los derechos humanos ya no se encuentre en el radar político, este tema no fue un foco de debate en esta ocasión. En particular en Chile, Lavín logro distanciarse de sus vínculos pinochetistas y armó una campaña que rehuía activamente estos temas. Su número de votos es prueba de que un gran segmento de la sociedad chilena no quiere escuchar del pasado pero sí, en cambio, de cómo se va a enfrentar el desempleo y las desigualdades de ingresos. Este tema, el de la desigualdad fue también una constante en los tres procesos. Asimismo, y en particular en Argentina y en Uruguay, otro tema clave fue el de la corrupción. La campaña UCR-Frepaso presentó un enfoque de reclamo ante los abusos de poder peronista que le cosechó muchos votos. Esta orientación también se pudo apreciar en la campaña de Tabaré Vásquez en Uruguay.

El mapa político de los tres países es incierto. En Chile la llegada de la derecha fue espectacular, pero resta comprobar si esta alianza de 
derecha sobrevivirá unida como oposición. En Uruguay es incierto si la correlación de fuerzas quedará en tres agrupáciones, Colorados, Blancos y Frente Amplio, o si los primeros dos se verán obligados a fusionarse para hacer frente a la izquierda. En Argentina después de una elección con tres partidos que se dividieron el poder, el escenario parece regresar a un bipartidismo poblado por una Alianza y los peronistas. Es necesario aguardar para dar la última palabra sobre la permanencia a largo plazo de la Alianza. El balance al interior de esta Alianza es precario y prevé que sus integrantes deberán superar los conflictos que supone gobernar juntos.

Por último, los tres países comparten un hecho fundamental. Aunque con disparidades, en las que no se puede ahondar es este espacio, Argentina, Uruguay y Chile han logrado democracias estables y participativas. Los comicios ocurren en un ámbito de transparencia, existe la posibilidad real de alternancia y la oposición se conduce de forma leal y responsable. 